\title{
An optimization clustering and classification based on artificial intelligence approach for internet of things in agriculture
}

\author{
Sakchai Tangwannawit ${ }^{1}$, Panana Tangwannawit ${ }^{2}$ \\ ${ }^{1}$ Department of Information Technology Management, Faculty of Information Technology and Digital Innovation, King Mongkut's \\ University of Technology North Bangkok, Bangkok, Thailand \\ ${ }^{2}$ Department of Mathematics and Computing Science, Faculty of Science and Technology, Phetchabun Rajabhat University, Phetchabun,
} Thailand

\begin{tabular}{l} 
Article Info \\
\hline Article history: \\
Received Aug 1, 2021 \\
Revised Dec 13, 2021 \\
Accepted Dec 29, 202 \\
\hline Keywords: \\
Agriculture \\
Artificial intelligence \\
Classification \\
Internet of things \\
Optimize clustering
\end{tabular}

\section{Corresponding Author:}

Panana Tangwannawit

Faculty of Sciences and Technology, Phetchabun Rajabhat University

Phetchabun, Thailand

Email: panana.t@gmail.com

\begin{abstract}
This research focused on testing with maize, economical crop grown in Phetchabun province, Thailand, by installing a total of 20 sets of internet of things (IoT) devices which consist of soil moisture sensors and temperature and humidity sensors (DHT11). Data science tools such as rapidminer studio was used for data cleansing, data imputation, clustering, and prediction. Next, these data would undergo data cleansing in order to group them to obtain optimization clustering to identify the optimum condition and amount of water required to grow the maize through k-mean technique. From the analysis, the optimization result showed 3 classes and these data were further analyzed through prediction to identify precision. By comparing several algorithms including artificial neural network (ANN), decision tree, naïve bayes, and deep learning, it was found that deep learning algorithm can provide the most accurate result at $99.6 \%$ with root mean square error (RMSE) $=0.0039$. The algorithm obtained was used to write function to control the automated watering system to make sure that the temperature and humidity for growing maize is at appropriate condition. By using the improved watering system, it improved the efficacy of watering system which saves more water by $13.89 \%$.
\end{abstract}

This is an open access article under the CC BY-SA license.

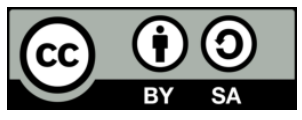

\section{INTRODUCTION}

Artificial intelligence (AI) is a technology to enable machines, computers, and statistical tools and equipment to create software that can imitate human capabilities especially on the very complex tasks e.g., memories, classification, reasoning, decision, prediction, and even communication with human beings, all through algorithms. In some cases, AI can be improved through self-learning which consists of 3 levels: machine learning [1], machine intelligence [2], and machine consciousness [3]. Machine learning is one of AI capabilities which the machine can learn on its own.

This research used a combination of internet of things (IoT), big data, and AI technology and integrated into agricultural system as a more effective alternative to help solve existing problems the farmers are facing. This could improve the speed, increase crop yields, and enable more effective use of natural resources for the users, or farmers which are the main objectives for this study. This research integrateds AI, IoT, and big data with 3 main actions: i) to analyze the classification of data to find optimum amount of 
water required, ii) to compare the algorithm of watering system, and iii) to improve the automated watering system based on the algorithm obtained.

\section{THEORETICAL BACKGROUND AND RELATED RESEARCH}

\subsection{Artificial intelligence (AI)}

AI technology works in between automated and intelligence system, it is crucial that the data obtained must be analyzed with the appropriate data classification, data types, and the relationship of the information from big data to use this analysis to decide instead of using human judgement to decide. This type of classification is suitable to create predictive modeling called supervised learning [4]. This type of classification of the data is to create model in grouping the data into assigned groups by create sample groups with data in advance and predict the data groups that have not been classified. The sample groups might be in a form of artificial neural network (ANN) [5], decision tree [6], naïve bayesian, and deep learning. This research compares the algorithms for the best efficiency.

\subsubsection{Artificial neural network (ANN)}

ANN is a type of self-learning similar to human brain system. Process involves bringing neural networks into the prediction which requires keying in the data to build simulation in data prediction in the future [7]. The artificial neural network will try to predict based on the built simulation to make sure there's as little error as possible, with the (1):

$$
n=\sum_{i=1}^{Z}=x_{i} w_{i}+b
$$

$\mathrm{n}=$ sum of function, $\mathrm{x}_{\mathrm{i}}=$ input $\mathrm{i}, \mathrm{w}_{\mathrm{i}}=$ weight $\mathrm{i}, \mathrm{z}=$ number of input layer, $\mathrm{b}=\mathrm{bias}, \mathrm{i}=1$ to $\mathrm{z}$.

\subsubsection{Decision tree (DT)}

Decision tree is a type of self-learning through mathematics to identify the best choice by creating data prediction in a form of tree structure which is learned through supervised learning. This enables clustering through training data set automatically and enable the group prediction of the data that has not been grouped before. In [8] the rank widget scores the attributes according to their correlation with the class. Attribute scoring methods that can be used in rank widget are information gain, information gain ratio and gini [9], [10].

\subsubsection{Naïve bayesian (NB)}

Naïve Bayesian (NB) is a type of learning through probability based on bayes theorem with a more straight forward, non-complex algorithm. It is a type of process in classifying information by learning from the problems occurred and utilize these conditions for re-classifying the data. It is a type of data classification that uses probability and computation to classify based on the hypothesis created with the data. The new calculated models will be used to adjust and re-classified which could either increase or reduce the probability of the information [11]. New information generated and set samples are then adjusted in combination with existing data, with the (2):

$$
P(A \mid B)=\frac{P(B \mid A) \times \mathrm{P}(A)}{P(B)}
$$

where $\mathrm{A}$ and $\mathrm{B}$ are the events and $P(B) \neq 0$

$P(A \mid B)$ the likelihood of event $\mathrm{A}$ occurring given that $\mathrm{B}$ is true.

$P(B \mid A)$ the likelihood of event $\mathrm{B}$ occurring give that $\mathrm{A}$ is true.

$P(A)$ and $P(B)$ are probabilities of observing $\mathrm{A}$ and $\mathrm{B}$ independently of each other.

\subsubsection{Deep learning}

Deep learning is a type of automated learning that imitates the function of human neural networks (neurons) by overlapping these neural networks into several layers and create learning of the sample data. These data mentioned will be used to detect patterns or arrange into category or classify the data. This use a multi layer feed forward neural network which uses back propagation for building the deep learning environment [12].

\subsubsection{Algorithm performance}

After that, testing data is conducted to evaluate the accuracy of the model (model evaluation) to be used to analyze the effectiveness of the algorithm operation obtained. In this research, the algorithm 
performance metrics used for experiment is accuracy and the evaluation of the algorithm operation is based on root mean square error (RMSE). Accuracy, with the (3):

$$
\text { Accuracy }=\left(\frac{T P+T N}{T P+T N+F N+F P}\right) \times 100
$$

RMSE, with the (4):

$$
R M S E=\sqrt{\frac{\left(a_{1}-y_{1}\right)^{2}+\ldots+\left(a_{n}-y_{n}\right)^{2}}{n}}
$$

\subsection{Internet of thing (IoT)}

IoT is a paradigm which connects sensors to the internet. This enables us to order and control the operation of different equipment [13] or circuit which detect the changes and showing the results as signals. [14] sensor samples such as humidity sensors, temperature sensors, immersion sensors, vibration sensors, current leakage sensors, and intelligent video sensors through smart phones or computer. This process then creates a smart system such as smart agriculture, smart device [15], smart grid [16], smart home, smart city [17], or smart transportation.

\subsection{Maize}

Maize has tall stems which can range from $60 \mathrm{~cm}$ up to 6 meters tall depending on the species. The diameter of the stem ranges from 1.27-5.08 cm. It takes approximately 100-120 days to be fully grown [18]. It is considered one of the economic crops in Thailand. In 2019-2020, it was found that the land for growing these crops throughout the country were declining. This is due to the fact that the land for growing these crops were left empty and farmers were unable to grow these crops due to drought from delays of rain and insufficient amount of natural water reserve. While the growing or crop is declining, there are still increasing demands of the maize in the country especially in farming business where maize is the main ingredient to make animal food for up to 7.41 million tons per year, while the annual supply is only 4.62 million tons [19].

\subsection{Literature review}

From Table 1 the review of all papers found that the fundamental of IoT has connecting physical objects, sensors, and other smart technologies altogether into one system. IoT is being utilized to view sensor values via the internet. Compilation of data obtained from IoT is used for analysis, clustering, classification, or prediction. Pulling these important data, big data, from several sensors from edge computing and data preprocessing allow information from data collection to be classified and completed. These data can either be with structure or without structure.

\begin{tabular}{|c|c|c|c|}
\hline & Methodology & Subject & Reference \\
\hline- & Cycle of smart farming. & IoT & {$[13]-[15]$} \\
\hline - & $\begin{array}{l}\text { Sensing and monitoring: robotics and sensors (temperature, humidity, and CO2), } \\
\text { greenhouse computers. }\end{array}$ & & $\begin{array}{c}{[17]} \\
{[20]-[22]}\end{array}$ \\
\hline- & $\begin{array}{l}\text { Analysis and planning: seeding, planting, soil typing, crop, health, yield modelling, } \\
\text { lighting, energy, and management. }\end{array}$ & & \\
\hline - & Control: precision farming, climate control. & & \\
\hline - & IoT definitions, technologies, and applications. & & \\
\hline- & IoT solution, devices, platform. & & \\
\hline - & Data collection: capture, storage, and transfer of data & Big data & [23], [24] \\
\hline- & $\begin{array}{l}\text { Data pre-processing: transformation, marketing, and analysis of Big Data, Big Data } \\
\text { greening, caching, remote sensing, real-time, analysis. }\end{array}$ & & \\
\hline- & $\begin{array}{l}\text { Choosing patten for AI; machine learning, machine intelligence, and machine } \\
\text { consciousness }\end{array}$ & AI & $\begin{array}{c}{[2],[3]} \\
{[25]-[28]}\end{array}$ \\
\hline
\end{tabular}

Table 1. Literature review methodology

The data classification methodology, it will be divided into 2 data sets. First, training set is a set of data used to train AI. This type of data is used to find variable which help the model function properly. While test set can measure the efficiency before bringing them to build AI. After that, choosing pattern for AI is conducted to select the appropriate algorithm. 


\section{RESEARCH METHOD}

From Figure 1 showed the steps to find algorithm is as follows:

\subsection{IoT}

Based on previous research, devices for the router node were installed which consists of Arduino Uno R3, soil moisture sensor, temperature and humidity sensor (DHT11), NODEMCU ESP8266 module, and battery pack as one set of installation. The entire research required 20 sets of the mentioned system to cover 1,200 square meters of land for the experiment with one set of the device with coordinator node, consisted of Arduino Uno R3, NODEMCU ESP8266, and water pump, shown in Figure 2. Each type of sensors receives the data in a form of analog and digital which required python language to improve by collecting data from the sensors through arduino board. Arduino board was used to read and deliver the data to cloud system through web service. Cloud system received the data and record them into database, firebase, by collecting, separating the data based on different measurements such as humidity and temperature from soil moisture sensor and DHT11. This information was passed through a wireless model NODEMCU ESP8266. The humidity and temperature sensors operated by having NODEMCU ESP8266 linked with wifi, sending the information through to firebase with data collection conditions to capture at 8 different times which was pre-designed since the start of the programming of arduino ide.

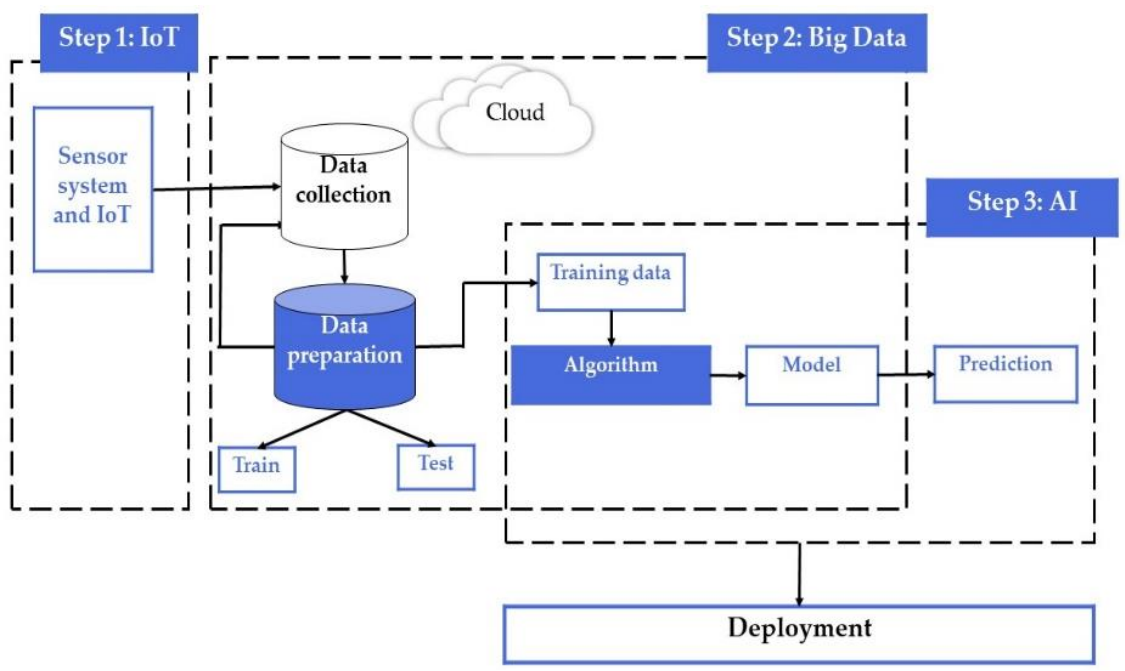

Figure 1. Framework of research method
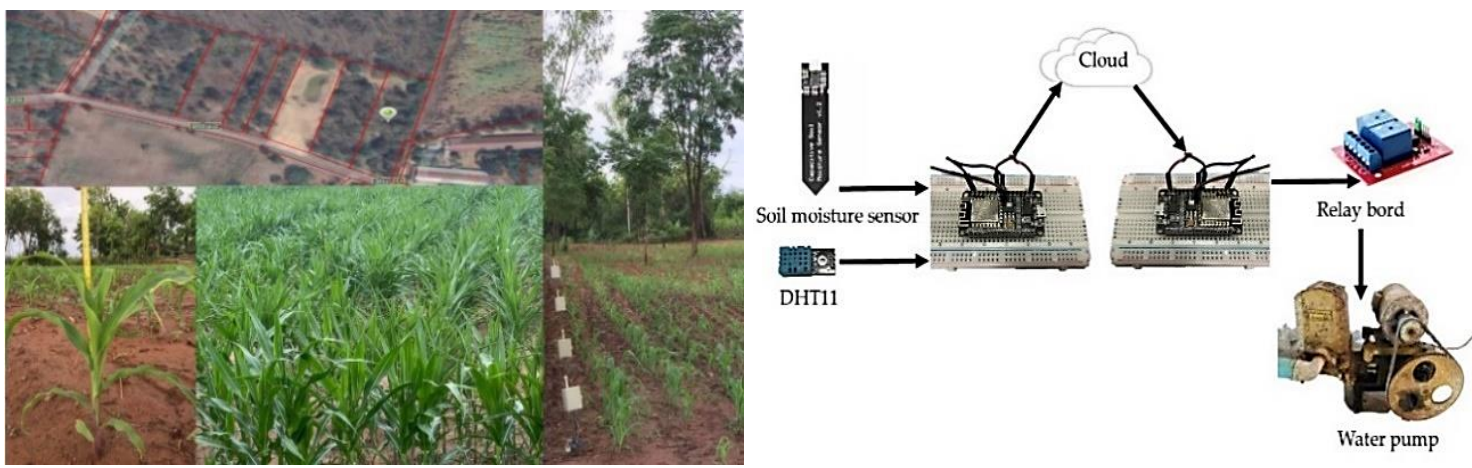

Figure 2. The prototype IoT and design of hardware sensors for maize area

\subsection{Big data}

Once data was received from the sensor (in step 1), application programming interface (API) was designed to receive the data from the devices and record them into the database by collecting them into the cloud computing. After that, improvement of cloud system was started by building the database for collecting 
humidity and temperature from each station. Data was then pulled from cloud system to analyze the appropriate value to predict the right amount of water to grow the crops in the future.

\subsection{AI}

From Figure 3, the steps to finding best algorithm for prediction. There are several tools available for the application of machine learning algorithms to data cleansing, imputation data, clustering, and prediction data. After a review of data science tools, RapidMiner is one of the best tools for data science and machine learning because it allows extremely fast and easy in data analytics [29].

Sensors captured the data every day for 30 consecutive days at 8 different time points: $1 \mathrm{am}, 4 \mathrm{am}$, $7 \mathrm{am}, 10 \mathrm{am}, 1 \mathrm{pm}, 4 \mathrm{pm}, 7 \mathrm{pm}$, and $10 \mathrm{pm}$. In total, there will be 20 data sets $\mathrm{x} 8$ different time points $\mathrm{x}$ 30 days $=4,800$ records. There might be some data lost when collecting from the sensors, so this research used cleansing and imputation with deep learning algorithm and assigned rectified linear unit (ReLU) technique to collect temperature and humidity data.

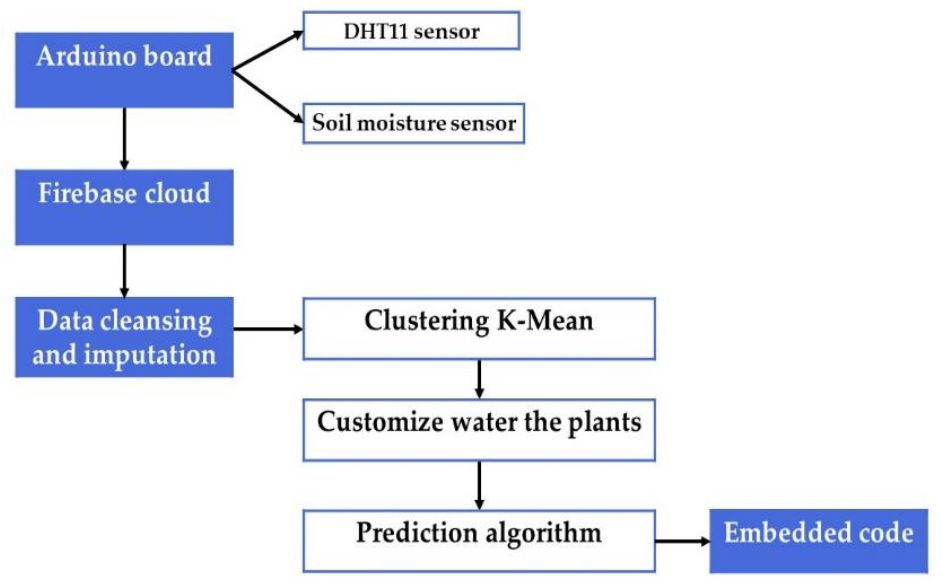

Figure 3. Steps for predictive model

After that, classifying the quality of the plantation with attributes such as time, station, temperature, humidity, and soil moisture were then tested with the k-mean clustering technique to identify the appropriate cluster. The result showed that the most appropriate cluster is cluster 3 where the elbow point and the best point from average within centroid distance is 34.643 and from davies bouldin is 0.959 as shown in Table 2 . After all 3 points were identified, different classes were created by giving high, medium, and no water to the crops.

Table 2. Result of optimize cluster

\begin{tabular}{ccc}
\hline Cluster & Davies bouldin & Average within centroid \\
\hline 2.0 & 1.138 & 54.710 \\
3.0 & 0.959 & 34.643 \\
4.0 & 1.023 & 29.628 \\
5.0 & 1.093 & 25.188 \\
\hline
\end{tabular}

Next, these 3 different classes were used in the experiment to provide the appropriate amount of water and monitor by using several sensors consisted of soil moisture sensor, DHT11 sensors to measure the temperature and soil moisture. It was found that for the class that require high amount of water, it needs a total of 15 minutes to water them, while 10 minutes is required for the class with medium amount of water. These conditions would create the soil that is moist enough to provide the appropriate condition for plantation. By analyzing the data with data selection, training data and test data were used with cross validation method to compare each model and create optimized parameter to find the most appropriate value in each model. From Table 3, the results from optimization of artificial neural network showed that the most appropriate value that was used to compare with other algorithms is the value of number of folds at 7 folds and training cycle at 18 cycles with accuracy at $99.37 \%$ and RMSE value $=0.0166$. The results from optimization of decision tree showed that the most appropriate value that was used to compare with other 
algorithms is the value of number of folds at 7 folds and gain ratio as criterion with the accuracy at $99.35 \%$ and RMSE $=0.0053$.

Table 3. Results from the algorithm comparison of the analysis of data on humidity and temperature

\begin{tabular}{ccc}
\hline Algorithm & Accuracy & RMSE \\
\hline Artificial neural network & $99.37 \%$ & 0.0166 \\
Decision tree & $99.35 \%$ & 0.0053 \\
Naïve bayesian & $97.46 \%$ & 0.0338 \\
Deep learning & $99.60 \%$ & 0.0039 \\
\hline
\end{tabular}

The results from optimization of naïve bayes showed that the most appropriate value that was used to compare with other algorithms is the value of number of folds at 11 folds with accuracy at $97.46 \%$ and RMSE $=0.0338$. The results from optimization of deep learning showed that the most appropriate value that was used to compare with other algorithms is the value of number of folds at 9 folds with accuracy at $99.60 \%$ and RMSE $=0.0039$. From the optimization, the best model was then created by looking at the accuracy and root mean square error, RMSE. The results showed that deep learning algorithm provided the highest accuracy at $99.60 \%$ with root mean square error at 0.0039 . From Figure 4 , the design and improvement of the automated watering system was divided into 2 main parts:

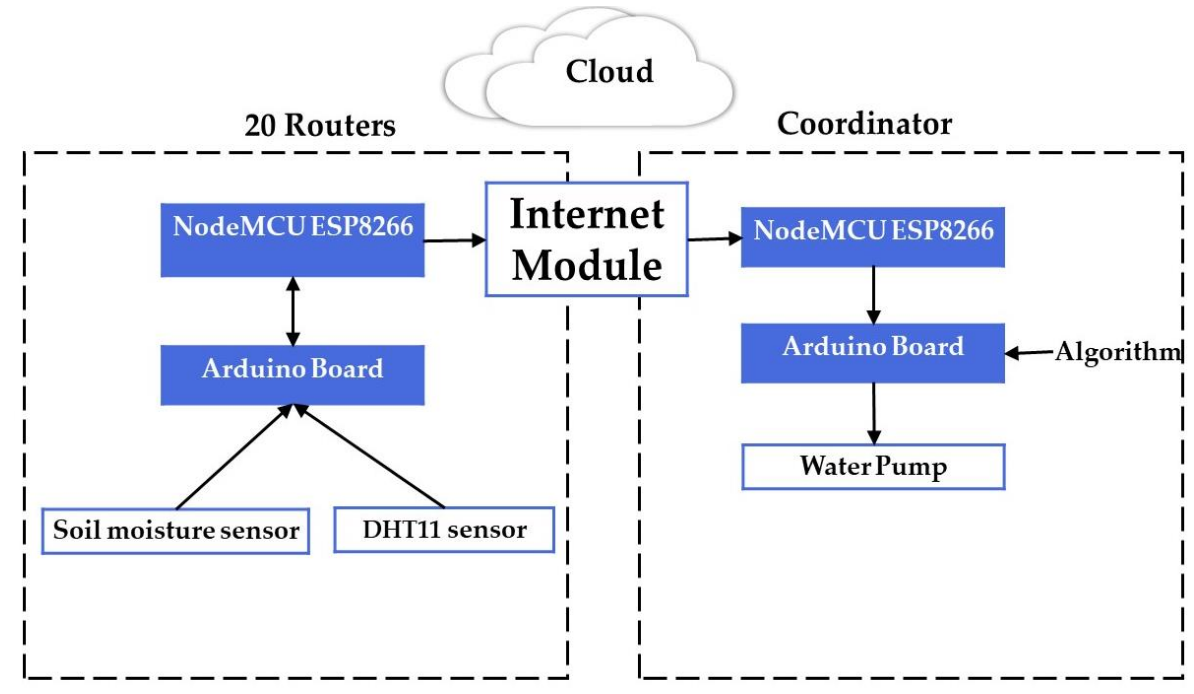

Figure 4. Data transmission between routers and coordinator

\subsubsection{Router node design}

Router node consisted of Arduino IDE board which connects to two different types of sensors. First was soil moisture sensor to measure the level of humidity in soil by installing the sensors at the roots of the maize at the $15 \mathrm{~cm}$ depth into the soil. Second, humidity and temperature sensor were used to measure the temperature. Both sensors indicated the needs of water for the maize through connecting with the wireless communication module, NODEMCU ESP8266, to send the sensor signals read from the arduino board to the coordinator node.

\subsubsection{Coordinator node}

The coordinator node consisted of two types of micro-controller boards which were arduino IDE and Node MCU with NODEMCU ESP8266 as communication module to receive the sensors from router node for the input of algorithm controller. This was to control the regulation of turning on and off of the water pump. The signal was sent to control the relay coordinator board which connected to the water pump to pump water into the watering system in the maize fields. Sensors received from the router nodes along with the status of all the pumps and solenoid valves was then sent up to the cloud service to record all the data and the status can be checked at monitored at real-time. Coordinator would receive data on temperature and humidity from the routers through NODEMCU ESP8266. These data would be analyzed with algorithm that 
was written in the Arduino board to control the water pump system in releasing the appropriate amount of water into the experiment area.

\section{RESULTS AND DISCUSSION}

4.1. Measure the amount of water used to grow maize through automated algorithm control

a. Measure the amount of water sprinklers in experimentation field with dimension of 60 meters in length $\times 20$ meters width: growing 1 row of maize with 60 meters length, distance in between each water sprinkler is at 30 centimeters. So, total of water sprinkler required for one row is equal to $6,000 / 30=200$ sprinklers. Growing total of 25 rows of maize will require a total of $200 \times 25=5,000$ water sprinklers for the experiment.

b. Measure the rate of water used per hour: total of 5,000 water sprinklers. Water flow rate is at 2.5 liters per hour per water sprinkler. So, the total water flow rate is $5,000 \times 2.5=12,500$ liters per hour.

c. From 30 days of data collection: it was found that the total duration required to water the entire area is 420 minutes or 6 hours and 30 minutes. So, the water rate is equivalent to $12,500 \times 6.5=81,250$ liters per month.

\subsection{Calculate the amount of water required to grow the maize through statistical methodology}

Watering the crops through statistical methodology required the calculation of amount of water needed for each type of plants with details as follows: evapotranspiration means the total amount of water lost from the planting area to the atmosphere in the form of steam which consisted of transpiration and evaporation process. The coefficient of water usage in each type of plants is unequal. The same type of plant might also have different water usage coefficient depending on the age as well. The water usage coefficient of maize can be referred from the data from department of agriculture [30] as shown in Table 4.

Table 4. Water usage coefficient of maize at different month of age [30]

\begin{tabular}{ccccccccccccccc}
\hline Month of age & 1 & 2 & 3 & 4 & 5 & 6 & 7 & 8 & 9 & 10 & 11 & 12 & 13 & 14 \\
\hline$K_{c}$ & 0.63 & 0.72 & 0.86 & 1.13 & 1.35 & 1.52 & 1.61 & 1.63 & 1.58 & 1.50 & 1.38 & 1.15 & 0.90 & 0.67 \\
\hline
\end{tabular}

Finding the amount of water usage of the plants referring to $E T_{p}$ can be calculated by relying on the statistic of the climate in Thailand from Meteorological Department, Ministry of Digital Economy and Society [31]. ETp of the planting area in Phetchabun province [32] was calculated as shown in Table 5.

Table 5. Amount of water used by plants referred to the planting area in Phetchabun province [31]

\begin{tabular}{lllllllllllll}
\hline Month & Jan & Feb & Mar & Apr & May & Jun & Jul & Aug & Sep & Oct & Nov & Dec \\
\hline$E T_{p}$ & 3.33 & 4.05 & 4.96 & 5.18 & 4.16 & 3.69 & 3.58 & 3.43 & 3.22 & 3.69 & 3.73 & 3.41 \\
\hline
\end{tabular}

The value then was calculated with this (5):

$$
E T=K_{c} \times E T_{p}
$$

$\mathrm{ET}=$ evapotranspiration, $\mathrm{K}_{\mathrm{c}}=$ crop coefficient, $\mathrm{ET}_{\mathrm{p}}=$ potential evapotranspiration.

The calculation of the amount of water required by maize was based on the duration of the experiment in starting in May 2021 which lasted for 1 month. Referring to the Table 4 and $5, \mathrm{~K}_{\mathrm{c}}$ equals 0.63 , $\mathrm{ET}_{\mathrm{p}}$ equal $4.16 \mathrm{~mm}$ per day.

$$
\begin{aligned}
& =0.63 \times 4.16 \\
& =2.6208 \mathrm{~mm} \text { per day }
\end{aligned}
$$

The amount of water required to grow maize in a month is equal to $2.6208 \times 30=78.624 \mathrm{~mm}$. Total amount of water needed for 1,200 square meters $=1,200$ square meters $x(78.624 / 1000 \mathrm{~mm})=94.3488$ cubic meters per month or approximately 94,349 liters per month which when compared to the amount of water used through the automated watering controller, it would require significantly less amount of water to grow the plants in the same area, with only 13,099 liters required for the automated water control. This can help save up to $13.89 \%$ of water usage within the 1,200 square meter planting area. 


\section{CONCLUSION}

This research used deep learning to identify the missing value which is a popular technique used for this type of research for data cleansing and imputation purpose. After that, the data underwent clustering to different groups with k-mean technique. Based on the temperature and soil moisture data, 3 classes of optimized data were obtained and used to identify the appropriate prediction value. By comparing the best accuracy value and RMSE value, it was found that deep learning algorithm resulted in the best value. Once algorithm was received, it was then written into the arduino board of the coordinator router to regulate the watering system. Sensor data from the router was further analyzed to provide the right amount of water based on the class predicted. Results from the experiment showed that after 30 days of testing, the new system can save $13.89 \%$ water more than the conventional system. For future work, more sensors should be installed to collect more information for further analysis such as sunlight sensors and mineral detectors in soil. This methodology can be applied to other types of plants and drone system can also be incorporated to collect data in a form of videos to analyze the growth of the crops or identify pests as well.

\section{ACKNOWLEDGEMENTS}

This research is supported by Faculty of Information Technology and Digital Innovation, KMUTNB and Faculty of Sciences and Technology, PCRU. This research is supported by the Thailand Science Research and Innovation, and Phetchabun Rajabhat University, with project No. 65A145000002.

\section{REFERENCES}

[1] P. Hebron, Machine learning for designers. O’Reilly Media, 2016.

[2] N. Buduma, Fundamentals of deep learning: designing next-generation machine intelligence algorithms. O'Reilly Media, 2017.

[3] A. Julianto and A. Sunyoto, "A performance evaluation of convolutional neural network architecture for classification of rice leaf disease," IAES International Journal of Artificial Intelligence (IJ-AI), vol. 10, no. 4, pp. 1069-1078, Dec. 2021, doi: 10.11591/ijai.v10.i4.pp1069-1078

[4] B. Annanurov and N. Noor, "A compact deep learning model for Khmer handwritten text recognition," IAES International Journal of Artificial Intelligence (IJ-AI), vol. 10, no. 3, pp. 584-591, Sep. 2021, doi: 10.11591/ijai.v10.i3.pp584-591.

[5] S. Verma, G. T. Thampi, and M. Rao, "ANN based method for improving gold price forecasting accuracy through modified gradient descent methods," IAES International Journal of Artificial Intelligence (IJ-AI), vol. 9, no. 1, pp. 46-57, Mar. 2020, doi: 10.11591/ijai.v9.i1.pp46-57.

[6] C. C. Aggarwal, "Training deep neural networks," in Neural Networks and Deep Learning, Cham: Springer International Publishing, 2018, pp. 105-167.

[7] O. I. Abiodun, A. Jantan, A. E. Omolara, K. V. Dada, N. A. Mohamed, and H. Arshad, "State-of-the-art in artificial neural network applications: a," Heliyon, vol. 4, no. 11, Nov. 2018, doi: 10.1016/j.heliyon.2018.e00938.

[8] L. Kanagasabai, "Shrinkage of power loss by enriched brain storm optimization algorithm," IAES International Journal of Artificial Intelligence (IJ-AI), vol. 8, no. 1, pp. 1-6, Mar. 2019, doi: 10.11591/ijai.v8.i1.pp1-6.

[9] R. S. El-Sayed and M. N. El-Sayed, "Classification of vehicles' types using histogram oriented gradients: comparative study and modification," IAES International Journal of Artificial Intelligence (IJ-AI), vol. 9, no. 4, pp. 700-712, Dec. 2020, doi: 10.11591/ijai.v9.i4.pp700-712.

[10] M. Morgan, C. Blank, and R. Seetan, "Plant disease prediction using classification algorithms," IAES International Journal of Artificial Intelligence (IJ-AI), vol. 10, no. 1, pp. 257-264, Mar. 2021, doi: 10.11591/ijai.v10.i1.pp257-264.

[11] T. A. Assegie, R. L. Tulasi, and N. K. Kumar, "Breast cancer prediction model with decision tree and adaptive boosting," IAES International Journal of Artificial Intelligence (IJ-AI), vol. 10, no. 1, pp. 184-190, Mar. 2021, doi: 10.11591/ijai.v10.i1.pp184190.

[12] S. Marzukhi, N. Awang, S. N. Alsagoff, and H. Mohamed, "RapidMiner and machine learning techniques for classifying aircraft data," Journal of Physics: Conference Series, vol. 1997, no. 1, Aug. 2021, doi: 10.1088/1742-6596/1997/1/012012.

[13] M. H. Ali and N. K. Ali, "IoT based security system and intelligent home automation multi monitoring and control systems," IAES International Journal of Robotics and Automation (IJRA), vol. 8, no. 3, pp. 205-210, Sep. 2019, doi: 10.11591/ijra.v8i3.pp205-210.

[14] A. H. Ali, A. H. Duhis, N. A. L. Alzurfi, and M. J. Mnati, "Smart monitoring system for pressure regulator based on IOT," International Journal of Electrical and Computer Engineering (IJECE), vol. 9, no. 5, pp. 3450-3456, Oct. 2019, doi: 10.11591/ijece.v9i5.pp3450-3456.

[15] V. S. Padala, K. Gandhi, and P. Dasari, "Machine learning: the new language for applications," IAES International Journal of Artificial Intelligence (IJ-AI), vol. 8, no. 4, pp. 411-421, Dec. 2019, doi: 10.11591/ijai.v8.i4.pp411-421.

[16] S. Chen et al., "Internet of things based smart grids supported by intelligent edge computing," IEEE Access, vol. 7, pp. 7408974102, 2019, doi: 10.1109/ACCESS.2019.2920488.

[17] S. Chatterjee, A. K. Kar, and M. P. Gupta, "Success of IoT in smart cities of india: an empirical analysis," Government Information Quarterly, vol. 35, no. 3, pp. 349-361, Sep. 2018, doi: 10.1016/j.giq.2018.05.002.

[18] "Agricultural economics of mize." Office of Agricultural Economics, Ministry of Agriculture and Cooperatives, 2020.

[19] "The study report project on suatainable consumtion and production of maize supply chain in Thailand," Mimistry for the Environment, Nature Conservation, 2018.

[20] P. Tangwannawit, "Development of of smart internet of things (IoT) for local vegetables," in The 15th National Conference and International Conference on Applied Computer Technology and Information Systems, 2019, pp. 134-146.

[21] A. Riansyah, S. Mulyono, and M. Roichani, "Applying fuzzy proportional integral derivative on internet of things for figs greenhouse," IAES International Journal of Artificial Intelligence, vol. 10, no. 3, pp. 536-544, Sep. 2021, doi: 10.11591/ijai.v10.i3.pp536-544. 
[22] P. Tangwannawit and K. Saengkrajang, "An internet of things secosystem for planting of coriander (Coriandrum sativum L.)," International Journal of Electrical and Computer Engineering (IJECE), vol. 11, no. 5, pp. 4568-4576, Oct. 2021, doi: 10.11591/ijece.v11i5.pp4568-4576.

[23] N. Seman and N. Atiqah Razmi, "Machine learning-based technique for big data sentiments extraction," IAES International Journal of Artificial Intelligence (IJ-AI), vol. 9, no. 3, pp. 473-479, Sep. 2020, doi: 10.11591/ijai.v9.i3.pp473-479.

[24] S. Tangwannawit and P. Tangwannawit, "Artificial intelligence theory and applications." Artificial Intelligence Association of Thailand, pp. 36-80, 2020.

[25] A. M. Abdu, M. M. M. Mokji, and U. U. U. Sheikh, "Machine learning for plant disease detection: an investigative comparison between support vector machine and deep learning," IAES International Journal of Artificial Intelligence (IJ-AI), vol. 9, no. 4, pp. 670-683, Dec. 2020, doi: 10.11591/ijai.v9.i4.pp670-683.

[26] A. Ullah, "Artificial bee colony algorithm used for load balancing in cloud computing: review," IAES International Journal of Artificial Intelligence (IJ-AI), vol. 8, no. 2, pp. 156-167, Jun. 2019, doi: 10.11591/ijai.v8.i2.pp156-167.

[27] N. A. K. Rosili, R. Hassan, N. H. Zakaria, S. Kasim, F. Z. C. Rose, and T. Sutikno, "A systematic literature review of machine learning methods in predicting court decisions," IAES International Journal of Artificial Intelligence (IJ-AI), vol. 10, no. 4, pp. 1091-1102, Dec. 2021, doi: 10.11591/ijai.v10.i4.pp1091-1102.

[28] N. A. Mashudi, N. Ahmad, and N. M. Noor, "Classification of adult autistic spectrum disorder using machine learning approach," IAES International Journal of Artificial Intelligence (IJ-AI), vol. 10, no. 3, pp. 743-751, Sep. 2021, doi: 10.11591/ijai.v10.i3.pp743-751.

[29] "RapidMiner reviews," platforms/vendor/rapidminer/reviews (accessed Feb. 28, 2021)

[30] "Reference crop evapotranspiration by penman monteith." Department of Agriculture, Thailand, 2019.

[31] "Water usage of the plants." Meteorological Department, Ministry of Digital Economy and Society, 2019.

[32] P. Tangwannawit and K. Saengkrajang, "Technology accept ance model to evaluate the adoption of the internet of things for planting maize," Life Sciences and Environment Journal, vol. 22, no. 2, pp. 262-273, 2021, doi: 10.14456/lsej.2021.13.

\section{BIOGRAPHIES OF AUTHORS}
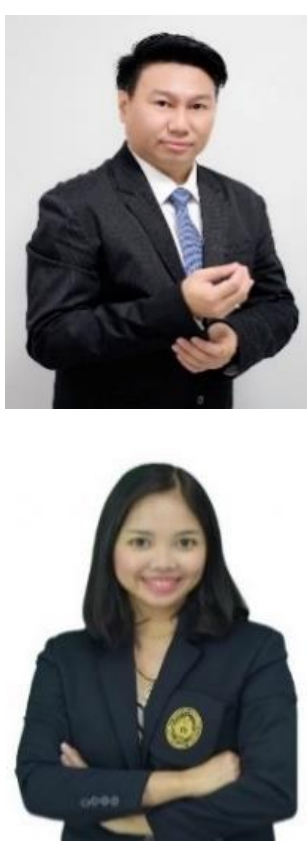

Sakchai Tangwannawit (D) SC P received the professional education with B.S. (Computer Science), M.S. (Information Technology), and Ph.D. (Computer Education) from King Mongkut's University of Technology North Bangkok (KMUTNB), Bangkok, Thailand. He has been working as a lecturer for more than 10 years in the field of Information Technology in the Faculty of Information Technology and Digital Innovation, KMUTNB. He can be contacted at email: sakchai.t@itd.kmutnb.ac.th.

Panana Tangwannawit (D) $\mathrm{SC}$ P received the professional education with B.S. (Computer Science), M.S. (Information Technology), and Ph.D. (Information Technology) from King Mongkut's University of Technology North Bangkok (KMUTNB), Bangkok, Thailand. She has been working as a lecturer for more than 24 years in the field of Computer and Information Technology in the Faculty of Sciences and Technology, Phetchabun Rajabhat University, Thailand. She can be contacted at email: panana.t@gmail.com. 